\title{
LIGHTNING INDUCED VOLTAGES ON OVERHEAD CONDUCTORS AT DIFFERENT HEIGIHTS
}

\author{
P.Durai Kannu and M. Joy Thomas \\ Department of High Voltage Engineering \\ Indian Institute of Science \\ Bangalore 560012, INDIA.
}

\begin{abstract}
The induced voltages due to a nearby lightning on an overhead conductor at different heights from the ground have been computed. The influence of finite ground conductivity on the induced voltages are analysed. It is observed that the finite ground conductivity influences the induced voltage on the conductors at lower heights $(\leq 20 \mathrm{~m})$ significantly. The influence of finite ground conductivity on the induced voltage for conductors at very large height $(\geq 100 \mathrm{~m})$ is found to be insignificant.
\end{abstract}

\section{Introduction}

The electric and magnetic fields produced by a lightning stroke in the vicinity of an overhead conductor can illuminate the conductor and it can acquire induced overvoltages which may be detrimental to the equipments connected to the line. The simulation of these transient phenomena is therefore important for the design of insulation coordination and protection schems. The magnitude and waveshape of the electromagnetic fields produced by lightning as well as the induced voltage on the overhead line are influenced by finite conductivity of the ground. In this paper, the induced transient voltages on overhead conductors at different heights due to a nearby lightning stroke to the ground are computed. The influence of finite ground conductivity on these induced voltages are analysed.

The main steps in computing the lightning induced voltage are

1. Modeling the lightning return stroke.

2. Estimating the fields generated by the lightning including the distortions introduced by the finitely conducting ground and

3. Modeling the field to overhead conductor coupling including the influence of ground impedance.

The ground conductivity plays a role both in the distortion of the radiated field as well as in the coupling of the field to overhead conductors. The aim of this paper is to study the effect of ground conductivity on the magnitude and waveshape of the induced voltage on conductors at different heights from the ground. The induced voltages were computed for two cases, viz., (i) an overhead conductor of $180 \mathrm{~m}$ long which is at a height of $113.5 \mathrm{~m}$ and (ii) an overhead conductor of $1000 \mathrm{~m}$ long which is at a height of $4.8 \mathrm{~m}$.

\section{The Analysis}

\section{A. Return Stroke Model}

The model adopted for lightning return stroke is the modified transmission line (MTL) model. In this model it is assumed that the current waveform at the ground decreases exponentially with height as it travels up the lightning channel at a constant velocfty $v$. Mathematically this current $i\left(z^{\prime}, t\right)$ at height $z$ and at time $t$ is represented by[1]

$$
i\left(z^{\prime}, t\right)=e^{\left(-z^{\prime} / \lambda\right)} i\left(0, t-z^{\prime} / v\right)
$$

where $\lambda$ is the decay constant to account for the effect of the vertical distribution of charge stored in the corona sheath of the leader and subsequent discharge during the return stroke phase. $i(0, t)$ is the lightning return stroke current at ground level (channel base current). In this paper the indiced voltages are computed for a channel base current of $10 \mathrm{kA}$ peak and maximum time derivative of $100 \mathrm{kA} / \mu \mathrm{s}[2]$. The lightning channel is assumed as straight and vertical.

The electric and magnetic field generated by the lightning return stroke are computed assuming the ground as a perfect conductor[3]. For the distances of few hundreds of meters from the lightning channel, the horizontal component of electric field is influenced by the finite conductivity of the ground. The horizontal component of the electric firld produced by the return stroke including the effect of ground conductivity is caculated wing Cooray-Rubirstein formula[4]

$E_{r g}(z=h, r)=E_{r}(z=h, r)-H_{\phi}(z=0, r) \frac{\sqrt{\mu_{0}}}{\sqrt{\epsilon+\sigma_{g} / j \omega}}$

where $E_{\tau}(z=h, r)$ is the Fourier-transform of the horizontal electric field at height $h, H_{\phi}(z=0, r)$ is the Fourier-transform of the azimuthal component of the magnetic field at ground level. $\epsilon$ is the permittivity of the ground. Both $E_{r}(z=h, r)$ and $H_{\phi}(z=0, r)$ are calculated assuming a perfect conducting ground.

\section{B. Field-to-Transmission line Coupling Model}

For the field-to-transmission line coupling, a set of time domain differential eqnations describing the voltages induced as proposed by Agrawal et.al.[5] have been 
used. For the computation of induced voltage on the overhead conductor, transmission line approximation has been used. The rise time for the chosen waveform is $0.8 \mu$ s. For this current waveform, the dominant frequency component ' $\mathrm{f}$ ' is $\mathbf{3 1 2 . 5} \mathbf{~ k H z}$. The corresponding wavelength, $\lambda(=c / f)$ is $960 \mathrm{~m}$.

If ' $\mathrm{h}$ ' is the height of the conductors above the ground, then the ratio $\frac{h}{\lambda}=\frac{113.5}{960}<<1$, and hence the transmission line approximation is valid for the computation of induced voltages for the largest height used in this study.

The surge propagation is affected by the ground impedance. This is represented in the overhead line parameters as i) per-unit series ground impedance and ii) shunt ground admittance. Both the above quantities are frequency dependent and generally the latter term is neglected. The frequency dependent series ground impedance is represented by a convolution integral in the time-domain coupling equations which are given as $[6]$

$$
\begin{gathered}
\frac{\partial}{\partial x}\left[v_{i}^{s}(x, t)\right]+\left[L_{i j}\right] \frac{\partial}{\partial t}\left[i_{i}(x, t)\right] \\
+\int_{0}^{t}\left[\xi_{i j}(t-\tau)\right] \frac{\partial}{\partial \tau}[i(x, \tau)] d \tau=\left[E_{x}^{i}\left(x, h_{i}, t\right)\right] \\
\frac{\partial}{\partial x}\left[i_{i}(x, t)\right]+\left[G_{i j}\right]\left[v_{i}^{s}(x, t)\right]+\left[C_{i j}\right] \frac{\partial}{\partial t}\left[v_{i}^{s}(x, t)\right]=0
\end{gathered}
$$

where $\left[E_{x}^{i}\left(x, h_{i}, t\right)\right]$ is the horizontal component of the incident electric field along the conductor at conductor height $h i$. The sub index $i$ denotes the particular wire of the multiconductor line. $\left[L_{i j}\right],\left[G_{i j}\right]$ and $\left[C_{i j}\right]$ are the inductance, conductance and capacitance matrices per unit length of the line respectively. $\left[i_{i}\right]$ is the line current vector. $\left[\xi_{i j}\right]$ is the transient ground resistance matrix and is equal to the inverse Fourier-transform of $\left[Z_{g_{i j}} / j \omega\right]$, ie., $\xi_{i j}(t)=F^{-1}\left[\frac{Z_{g_{j j}}}{j \omega}\right]$ and $\left[Z_{g_{i j}}\right]$ is the ground impedance matrix. The internal impedance of the line is neglected. $\left[v_{i}^{8}\right]$ is the scattered voltage vector on the $i^{\text {th }}$ conductor. This is the voltage due to the field produced by the induced currents on the conductors. The scattered voltage is related to the total line voltage $v_{i}(x, t)$ hy the following relation.

$$
\left[v_{i}(x, t)\right]=\left[v_{i}^{s}(x, t)\right]+\left[v_{i}^{i}(x, t)\right]
$$

where $\left[v_{i}^{i}(x, t)\right]$ is the incident voltage.

$$
\left[v_{i}^{i}(x, t)\right]=-\int_{0}^{h_{i}} E_{z}^{i}(x, z, t) d z
$$

$E_{z}^{i}(x, z, t)$ is the incident(or inducing) vertical electric field at $x$ at a height of $z$.

The voltage at the end of the line is determined by

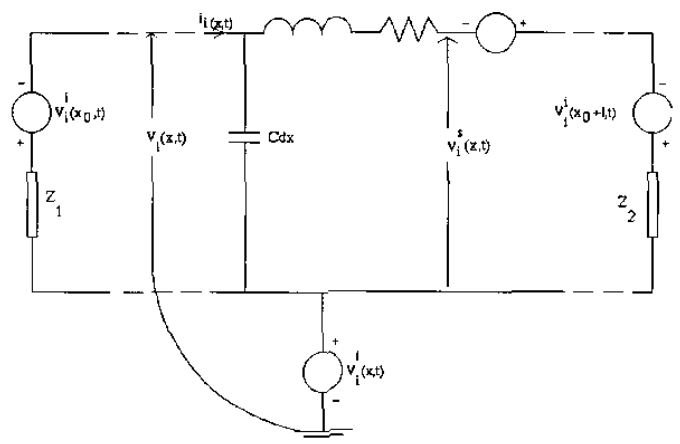

Fig. 1. Equivalent circuit of a single-wire overhead line excited by lightning return-strokeelectromagnetic field. Conductance is neglected.

the boundary condition and the current at the two ends of the line, viz., $i\left(x_{0}, t\right)$ and $i\left(x_{0}+1, t\right)$, where $l$ is the length of the overhead line. The boundary conditions for the scattered voltage are

$$
\begin{gathered}
v_{i}^{s}\left(x_{0}, t\right)=-\left[Z_{1}\right]\left[i_{i}\left(x_{0}, t\right)\right]+\int_{0}^{h_{i}} E_{z}^{i}\left(x_{0}, z, t\right) d z \\
v_{i}^{s}\left(x_{0}+l, t\right)=\left[Z_{2}\right]\left[i_{i}\left(x_{0}+l, t\right)\right]+\int^{\prime \prime l} E_{z}^{i}\left(x_{0}+l, z, t\right) d z
\end{gathered}
$$

where $\left[Z_{1}\right]$ and $\left[Z_{2}\right]$ are the terminating impedance matrices.

The equivalent circuit for this coupling model for a single conductor excited by the external electromagnetic field is shown in fig 1. Equations (3) and (4) were solved by finite difference time domain(FDTD) method.

\section{Results and Discussion}

The lightning striking location is chosen as $50 \mathrm{~m}$ away from the conductor mid point and perpendicular to it. The line is terminated by the surge impedance of the line for both the cases. The induced voltages were computed at the line termination as well as at line mid point.

Figure 2 shows the induced voltage calculated at the line termination for a conductor of length $1000 \mathrm{~m}$ and a height of $4.8 \mathrm{~m}$. Figure 3 shows the calculated induced voltage at line termination for a conductor of length $180 \mathrm{~m}$ and a height of $\mathbf{1 1 3 . 5} \mathrm{m}$ above the ground. From the figures $\mathbf{2}$ and $\mathbf{3}$, it can be observed that the influence of finite ground conductivity on the induced voltages on an overhead line at lower height(ie., at 4.8 $\mathrm{m}$ above the ground) is more, whereas its influence on the induced voltage on the conductor at large height(ie., at $113.5 \mathrm{~m}$ above the ground) is insignificant 


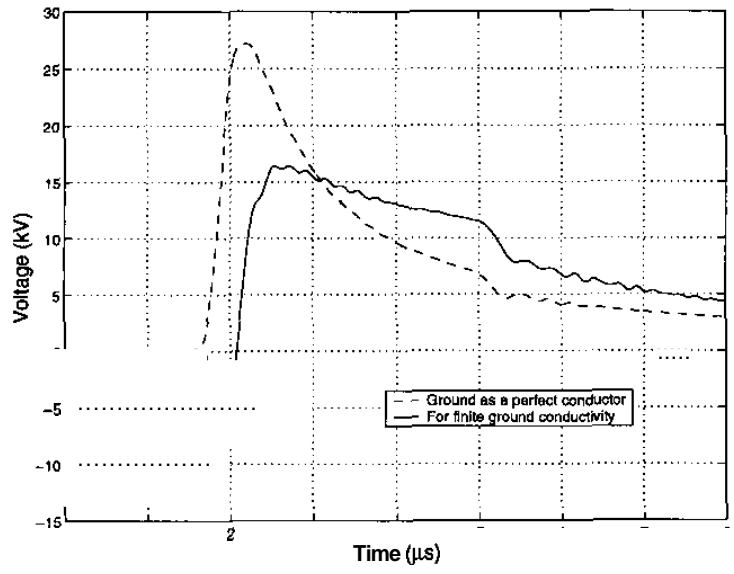

Fig, 2. Induced voltage at line termination for a canductor length of $1000 \mathrm{~m}$ and at a height of $4.8 \mathrm{~m}$. The ground parameters are $\sigma_{g}=0.001 \mathrm{~S} / \mathrm{m}$ and $\varepsilon_{r}=10.0$.

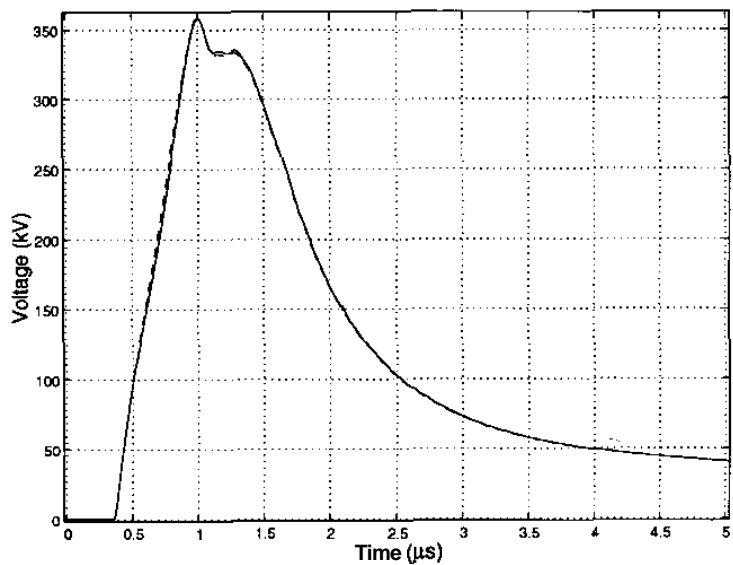

Fig. 3. Induced voltage at line termination for a conductor of length $180 \mathrm{~m}$ which is at a height of $113.5 \mathrm{~m}$. Solid line ground as a perfect conductor, - for a finitely conducting ground. The ground parameters are $\sigma_{g}=0.001 \mathrm{~S} / \mathrm{m}$ and $\epsilon_{r}=10.0$.

The influence of finite ground conductivity on the induced voltage on overhead conductor can be analysed as follows. In the Agrawal's model for the fieldto-conductor coupling, the vertical and the horizontal electric fields are the source terms. For distances of few hundreds of meters away from the lightning charnel, the vertical electric field is not influenced much by the finite ground conductivity, whereas the horizontal electric field is influenced by the finite ground conductivity. The horizontal electric field assuming ground as a perfect conductor as well as for the ground parameters $\sigma_{g}=0.001 \mathrm{~S} / \mathrm{m}$ and $\epsilon_{r}=10$ are shown in figure 4 . From the figure 4, it can be seen that the finite ground conductivity influences the horizontal electric field at lower height, whereas its influence is insignificant for larger height.

The induced voltage on the overhead conductor is due to the contribution from vertical and horizontal components of the electric field. Figures 5 and 6 show the induced voltages at line termination due to (i) ver-
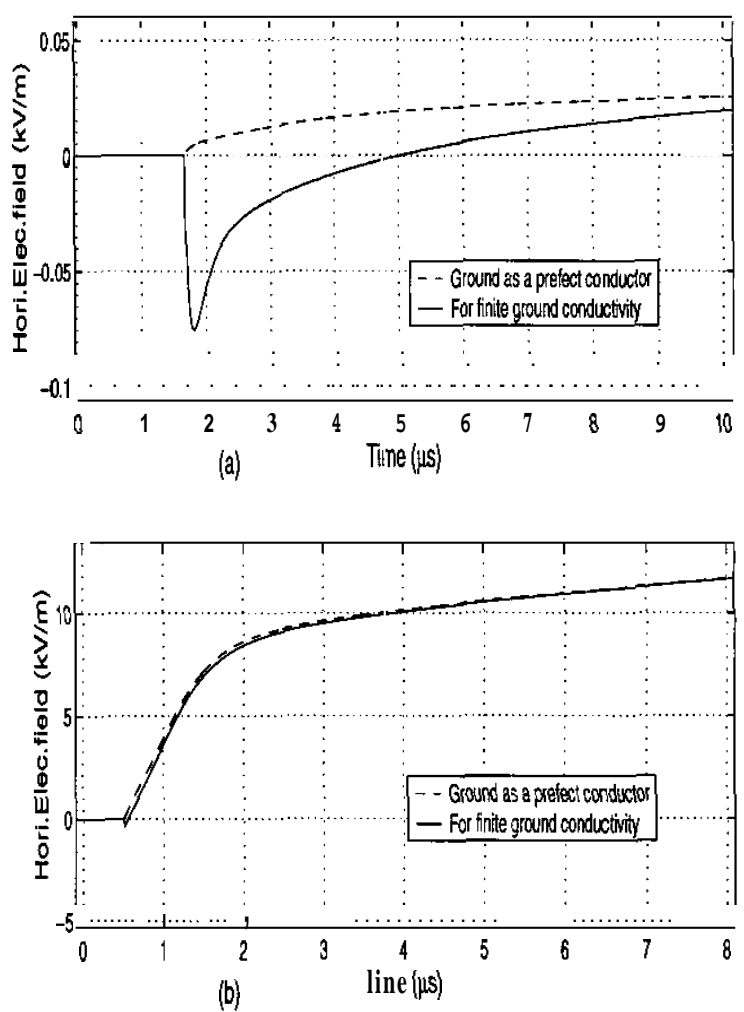

Fig. 4. Horizontal electric field calculated (a) at a distance of 500 $\mathrm{m}$ form the lightning channel and at height of $4.8 \mathrm{~m}$ above the ground (b) at a distance of $103 \mathrm{~m}$ from the lightning channel and at a height of $113.5 \mathrm{~m}$ \% bove the ground.

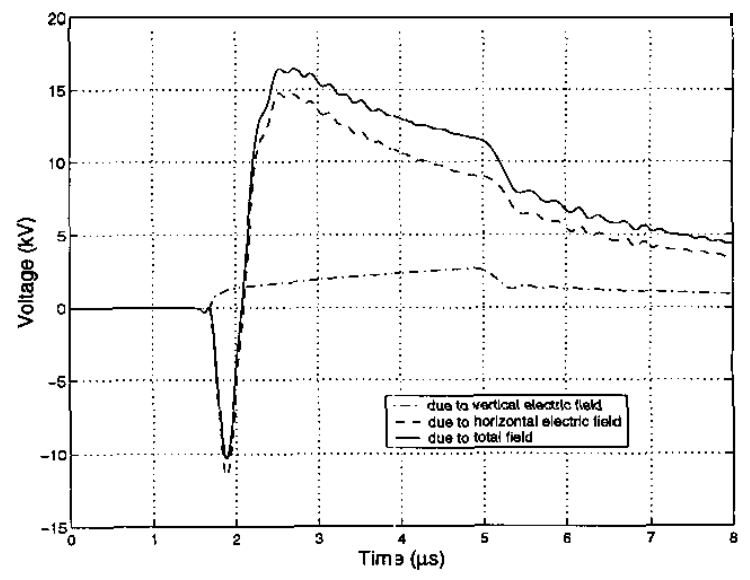

Fig, 5, Induced voltage at line termination for a conductor length of $1000 \mathrm{~m}$ and at a height of $4.8 \mathrm{~m}$. The ground parameters are $\sigma_{g}=0.001 \mathrm{~S} / \mathrm{m}$ and $\epsilon_{\Gamma}=10.0$. 


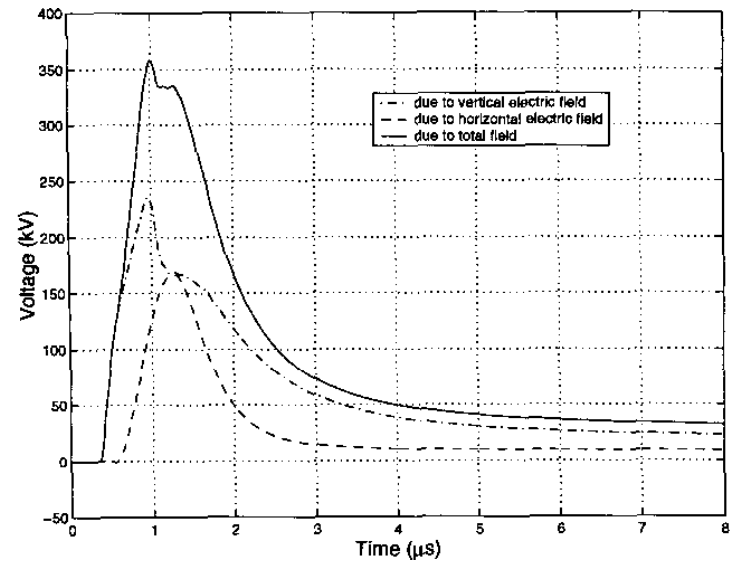

Fig. 6. Induced voltage at line termination for a conductor of length $180 \mathrm{~m}$ which is at a height of $113.5 \mathrm{~m}$. The ground parameters are $\sigma_{g}=0.001 \mathrm{~S} / \mathrm{m}$ and $\epsilon_{r}=10.0$

tical electric field (ii) horizontal electric field and (iii) both vertical and horizontal electric fields or total field. For the conductor of length $1000 \mathrm{~m}$ and a height of $4.8 \mathrm{~m}$ above the ground, the contribution of horizontal electric field on total induced voltage is much higher than the contribution due to vertical electric field(as shown in figure 5). In this case, the contribution due to horizontal electric field excitation is more since the span is more $(1000 \mathrm{~m})$. Also the vertical electric field is integrated for a lower height $(4.8 \mathrm{~m})$ only. The electric field contains three components viz., static, induction and radiation. The initial negative polarity in the induced voltage at the line termination is due to the radiation component of the electric field[7]. But for the conductors at large heights $(113.5 \mathrm{~m})$, the contribution of vertical electric field on total induced voltage is more. This is because since the line length is small, the span over which the horizontal electric field excitation is active is also less and the influence of ground conductivity on the horizontal electric field at such a large height $(113.5 \mathrm{~m}$ ) is also insignificant (as shown in figure 4). Moreover, the vertical electric field is integrated for a larger height $(113.5 \mathrm{~m})$ and hence its contribution $\mathrm{b}$ e comes dominant as compared to the contribution due to horizontal electric field.

The computed induced voltages at the line mid points for the conductors at $4.8 \mathrm{~m}$ and $113.5 \mathrm{~m}$ height above the ground are shown in the figures 7 and 8 re spectively. From these two figures it is seen that the finite ground conductivity increases the magnitude of the induced voltages(for the lightning striking location studied). The influence is more for the conductor of $1000 \mathrm{~m}$ in length and at a height of $4.8 \mathrm{~m}$, whereas the influence of finite conductivity is insignificant for the conductor at $133.5 \mathrm{~m}$ height and $180 \mathrm{~m}$ long.

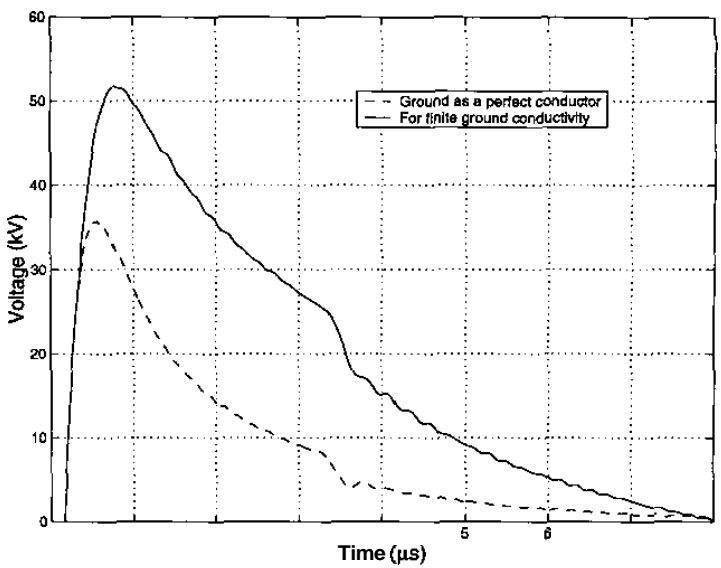

Fig. 7. Induced voltage at line mid point for the conductor of length $1000 \mathrm{~m}$ which is at a height of $4.8 \mathrm{~m}$. The ground parameters are $\sigma_{g}=0.001 \mathrm{~S} / \mathrm{m}$ and $\epsilon_{r}=10.0$.

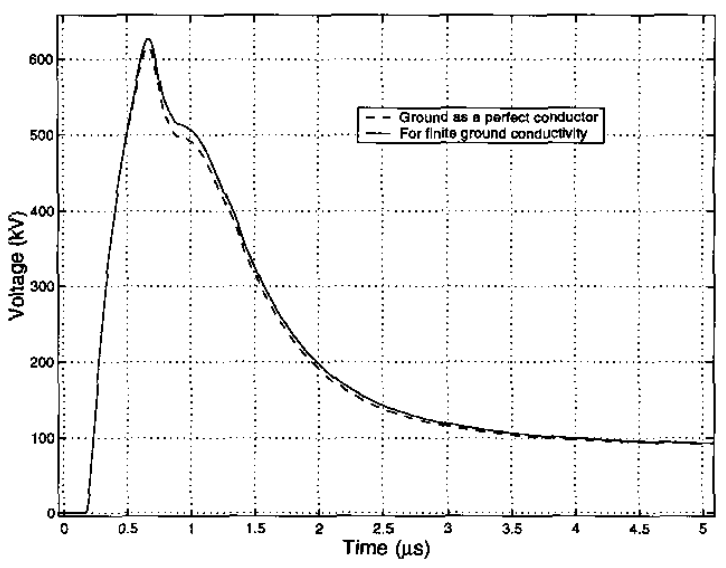

Fig. 8. Induced voltage at line mid point, for the conductor of length $180 \mathrm{~m}$ which is at a height of $113.5 \mathrm{~m}$. The ground parameters are $\sigma_{g}=0.001 \mathrm{~S} / \mathrm{m}$ and $\epsilon_{r}=10.0$.

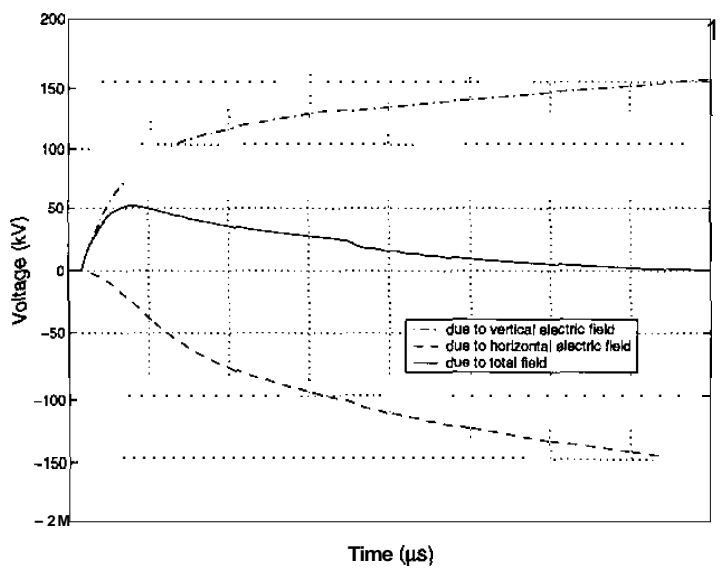

Fig. 9. Induced voltage at line mid point for the conductor of length $1000 \mathrm{~m}$ which is at a height of $4.8 \mathrm{~m}$. The ground parameters are $\sigma_{g}=0.001 \mathrm{~S} / \mathrm{m}$ and $\epsilon_{r}=10.0$. 


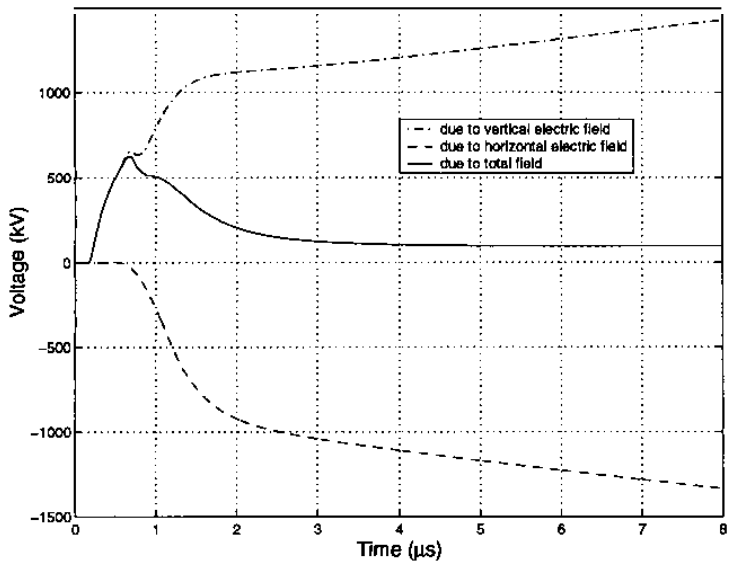

Fig. 10. Induced voltage at line mid point, for the conductor of length $180 \mathrm{~m}$ which is at a height of $113.5 \mathrm{~m}$. The ground parameters are $\sigma_{g}=0.001 \mathrm{~S} / \mathrm{m}$ and $\epsilon_{\tau}=10.0$.

Figures 9 and 10 shows the induced voltage at line mid point on the above mentioned conductors due to vertical field, horizontal field and the total field. Comparing the figures 5, 6,9 and 10, the following can he observed. For the lightning striking location chosen (i) the induced voltage due to vertical electric field is positive at line termination as well as at line mid point, and (ii) the induced voltage due to horizontal electric field is positive at line termination (initial negative is due to finite ground conductivity) whereas it is negative at line mid point. Since the influence of finite ground conductivity is to reduce the magnitude of the horizontal field in the initial period (see figure $4(\mathrm{a})$ )), its influence on the induced voltage is less. That is, due to finite ground conductivity, the horizontal electric field contribution(positive magnitude at line termination and negative magnitude at line mid point) on the induced voltage are reduced. Hence, the induced voltage decreases at line termination and increases at line mid point due to finite ground conductivity for the lightning striking location chosen.

Therefore, for an overhead conductor of shorter length and larger height, the Contribution of vertical electric field to the induced voltage is more, where as for a longer conductor at lower height from ground, the contribution of horizontal electric field to the induced voltage is more. For a conductor of longer length and lower height, where the horizontal electric field Contribution to the total induced voltage is more, the influence of ground Conductivity becomes significant. In contrast, the horizontal electric field at large heights $(113.5 \mathrm{~m})$ is not influenced by the finite ground conductivity (as shown in figure 4).

\section{Conclusions}

The induced voltage or. an overhead conductor at two different heights due lo a nearby lightning have been computed. From the study it is seen that the finite ground conductivity significantly influences the magnitude as well as the waveshape of the induced voltage for conductors which are at a lower height $(\leq 10 \mathrm{~m})$. The influence of finite ground conductivity on the induced voltage on conductors at larger height is insignificant.

\section{References}

[1] C.A.Nucci, F.Rachidi, M.V.Ianoz and C.Mazzetti, "Lightning Induced Voltages on Overhead Lines", IEEE Trans.Electromagnetic Compatibility, Vol.35, No.1, pp 75 85, February 1993.

[2] A.Zeddain and P.Deganque, "Current and Voltage Induced on Telecommunicaticiss Cable by a Lightning Return Stroke", in Lightning Electromagnetics, R. L Gardner, Ed, New York, Hemisphere, pp 377-400, 1990.

[3] M.J.Master and M.A.Uman, "Lightning Induced Voltages On Power Lines: Theory", IEEE Transactions an Power Apparatus and Systems, Vol.PAS-103, No.9, pp 2502-2515, September 1984.

[4] M.Rubinstein, 'An Approximate Formula for the Calculation of the Horizontial Electric Field from Lightning at Close, Intermediate, and Long Range", IEEE Trans.Electromagnetic Compatibility, Vol.38, No.3, pp 531535, August 1996 .

[5] A.K. Agrawal, H.J. Price and S.H. Gurbaxani, "Transient Response of Multiconiductor Transmission Lines Excited by a Nonuniform Electromagnetic Field", IEEE Trans.Electromagnetic Compatibility, Vol.EMC.22, No.2, pp 119-129, May 1980.

[6] F.Rachidi, C.A.Nucci, M.Ižnoz and C.Mazzetti, "Influence of a lossy Ground on Lightning-Induced Voltages on Overhead Lines", IEEE Trans.Electromagnetic Compatibility, Vol.38, No.3, pp 250-264, August 1999 .

[7] P. Durai Kannu and M. Joy Thomas, "Influençe of Lightning Electric Field Components on the Induced Voltages on a Power Distribution Line", Electric Power Systems Research. Vol.64, No.3, pp 247-255, Mlarch 2003. 